\title{
Nifty transport device doubles durability of donor organs
}

In the past few months, an egg-shaped device about the size of a carry-on suitcase has made several appearances in New York: on a pedestal at the Smithsonian Cooper-Hewitt National Design Museum, in the permanent collection of the Museum of Modern Art and in the transplant surgery suites at some of the city's biggest hospitals.

Depending on whom you ask, it's a work of art, a useful piece of diagnostic equipment or, perhaps, the long-sought solution to the chronic shortage of donor kidneys. "Briefly, it's our alternative to the beer cooler," says David Kravitz, chief executive officer of Illinois-based Organ Recovery Systems, maker of the LifePort kidney transporter.

A glorified beer cooler has for decades been the vehicle of choice to transport precious organs meant for transplant surgeries. The LifePort, a portable, fully automated system, began taking the cooler's place with approval from the US Food and Drug Administration in 2003 and from European regulators in 2004.

The machine perfuses the organ, meaning that it pumps buffered temperature-controlled nutrients through the donor kidney's blood vessels. This nearly doubles the organ's viability from a usual maximum of 24 hours to 41 hours.

Some studies suggested that this method may cut the chances of the recipient's body rejecting the kidney, but those studies were too small to be conclusive.

Rutger Ploeg, general secretary of the European Society for Organ Transplantation, and his colleagues are finishing up a trial of 338 participants in multiple centers, comparing the LifePort with a standard cooler. The results are expected to be announced at the society's October meeting in Prague.

In part because of the $\$ 18,000$ price tag, few transplant organizations have so far adopted the LifePort, but some are already sold on the machine's benefits.

For example, for preserving older, sicker donor kidneys that might otherwise be discarded, the LifePort has proven superior, says Jeffrey Lewis, director of donor referral and recovery services at the New York Organ Donor Network.

Other machines have been available for decades, but most require a tabletop and an electrical outlet. Because it is portable and fully automated, the LifePort makes it possible to keep perfusing the organ continuously during transport.

In New York and other large transplant centers, where the demand for kidneys vastly outstrips the supply, bringing in surplus organs from other areas poses a tremendous challenge.

The LifePort, which can be shipped unattended on commercial airliners, "definitely allows us to use organs from outside the area and extend their cold time," says Susan Lerner, assistant professor of surgery at Mount Sinai School of Medicine in New York.

The LifePort also allows researchers to collect useful information about the organ. A kidney that offers high resistance to the fluid flowing through it, for example, is less likely to function

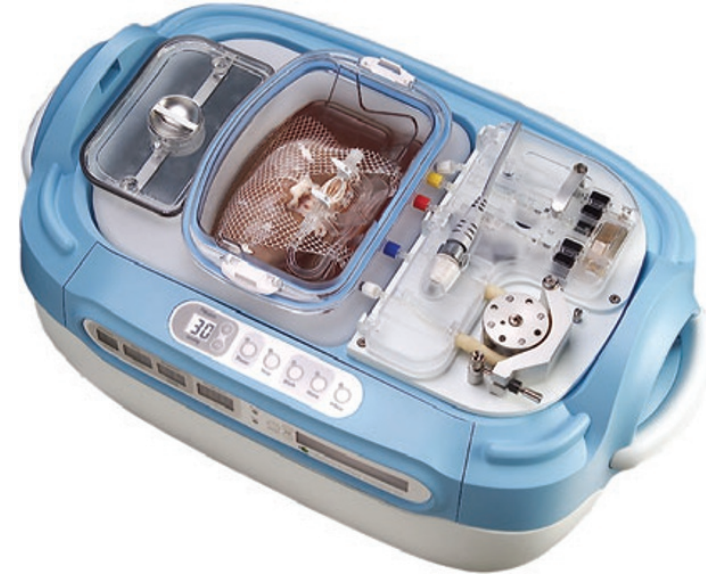

Hot to trot: The fancy alternative to a beer cooler promises to extend donor kidney's lifespan.

well in the recipient, Lerner explains. Identifying such biomarkers for kidney function might help design ways to treat the organs before the transplant.

Data from the LifePort might also help salvage organs that transplant networks previously rejected outright, such as kidneys from deceased donors with complicated medical histories. "It has really increased the donor pool significantly," Lerner says.

The company is developing similar models for other organs, including livers, hearts and intestines, but is reticent about the details. "If you can find a way to extend the life outside the body of those organs," says Lerner, "then you can really do wonders."

Alan Dove, New York

\section{Critics slam Russian trial to test pig pancreas for diabetics}

An Australian company's trial to test pig pancreatic cells in people as a treatment for diabetes is drawing strong criticism from leading researchers and ethicists.

The method does not have enough credibility to proceed with the trial in humans, the critics caution.

Melbourne-based Living Cell Technologies (LCT) announced in February that Russian authorities had approved a human trial of its DiabeCell treatment, in which pancreatic beta cells-which produce insulin-are encapsulated in a seaweed-derived gel. Small pores in the gel allow the passage of nutrients, waste material and insulin but block immune cells, eliminating the need for immunosuppressive drugs, the company says.

In the trial set to begin by mid-year, six adults who have had diabetes for at

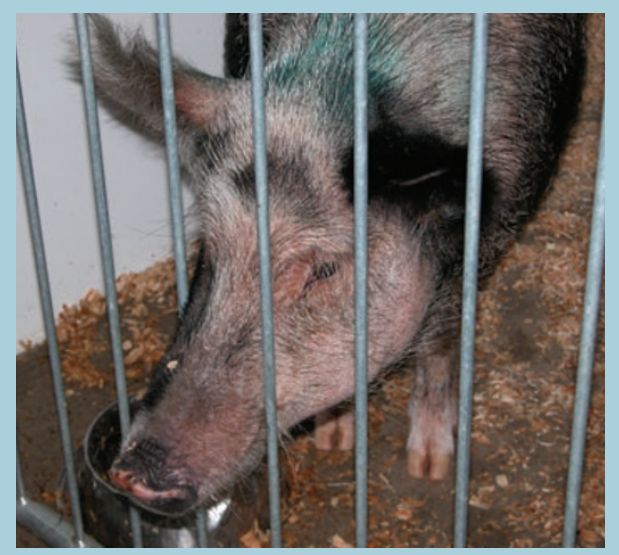

Pancreatic cells from pigs like this one will be transplanted into people with diabetes. least ten years will receive two transplants each of approximately 5,000 encapsulated pig pancreatic islet cells. Nicolai Skaletsky, a researcher at Moscow's Sklifosovski Institute, is hosting and funding the trial, which will be managed by Massachusettsbased research contractor Geny Research.

Preliminary results with this approach in animal models have been encouraging, but it is premature to test the treatment in humans, warns Megan Sykes, president of the International Xenotransplantation Association and professor of surgery at Harvard Medical School.

Of seven journal articles cited on the company's website as proof of the method's potential, Sykes says three are inaccurately documented and only two of the remaining four deal with the encapsulated pig islet technology. "Neither of them convincingly 